\title{
MICROENCAPSULAÇÃo DE ÁCIDO ASCÓRBICO EM PÓ DE ACEROLA VERDE OBTIDO POR SPRAY DRYING
}

\author{
L. M. L. SANTOS ${ }^{1}$, J. L. MUNIZ1, A. P. M. PIRES², R. S. ARAÚJO'1,2 \\ ${ }^{1}$ Instituto Federal do Ceará - Campus Limoeiro do Norte - Mestrado em Tecnologia de \\ Alimentos \\ ${ }^{2}$ Instituto Federal do Ceará - Campus Fortaleza - Departamento de Química e Meio Ambiente \\ E-mail para contato: luana@ifce.edu.br
}

\begin{abstract}
RESUMO - A microencapsulação de substâncias quimicamente sensíveis por spray drying tem se mostrado viável para obtenção de sucos desidratados, concentrando as substâncias ativas típicas e protegendo-as em uma matriz polimérica contra a oxidação. $\mathrm{O}$ presente trabalho se propôs a microencapsular ácido ascórbico (AA) obtido a partir do suco de acerola verde in natura avaliando-se a influência dos parâmetros de temperatura de secagem, fluxo de ar, vazão de alimentação e taxa de aspiração sobre a composição centesimal do pó obtido. Maltodextrina (20\%) foi adicionada como agente de encapsulamento ao suco de acerola verde (teor inicial de 2,8\% de AA). Os resultados obtidos para um taxa de alimentação de $9 \mathrm{~mL} \cdot \mathrm{min}^{-1}$ sob uma temperatura de secagem de $165{ }^{\circ} \mathrm{C}$, fluxo de ar de $473 \mathrm{~L} \cdot \mathrm{h}^{-1}$ e taxa de aspiração de $35 \mathrm{~m}^{3} \cdot \mathrm{h}^{-1}$ mostraram um pó com alta solubilidade em água e teor final de AA de aproximadamente $17 \%$. A composição centesimal média para o suco reconstituído apresentou teores de $2,5 \%$ de AA; $0,5 \%$ de cinzas; $1 \%$ de proteínas; $5,5 \%$ de açúcares totais e $90 \%$ de umidade.
\end{abstract}

\section{INTRODUÇÃO}

A acerola (Malpighia emarginata D.C) é um fruto nativo das ilhas do Caribe, América Central e norte da América do Sul, sendo cultivada comercialmente, no Brasil, desde meados dos anos 80, principalmente no Nordeste, com destaque para os estados de Pernambuco, Paraíba, Bahia e Ceará; por suas condições de solo e clima (RITZINGER e RITZINGER, 2011). Ferreira et al. (2009) relatam que a acerola apresenta-se atrativa pelo seu sabor agradável e destaca-se por seu potencial nutricional, principalmente como fonte de vitamina $\mathrm{C}$, razoável fonte de pró-vitamina $\mathrm{A}$, ferro, cálcio e vitaminas do complexo B (tiamina, riboflavina e niacina).

Durante seu amadurecimento o fruto passa por uma série de alterações bioquímicas destacandose uma acentuada perda de ácido ascórbico (AA), do estágio verde ao maduro, conforme Vendramini e Trugo (2000). Segundo Tanaka (2007), o fruto apresenta grande potencial de aproveitamento industrial tanto na área alimentícia como na farmacêutica, o que tem atraído interesse dos fruticultores de várias regiões do Brasil. 


\section{9 a 22 de outubro de 2014 \\ Florianópolis/SC}

A acerola apresenta uma curta vida pós-colheita com perdas de $40 \%$, em função da sua elevada taxa respiratória e de sua estrutura frágil, sendo necessária a utilização de técnicas de processamento adequadas para prolongar o período de conservação das frutas, preservando a sua qualidade (MATSUURA, 2011). Ferrari et al. (2012) apresentam a secagem por spray drying como uma alternativa viável para a conservação de substâncias termossensíveis presentes nos frutos. O processo é indicado para produtos pastosos ou líquidos e caracteriza-se pela pulverização da amostra e sua transformação em um produto seco, na forma de pó, em um tempo relativamente curto. De acordo com Bhandari et al. (1997), o alto teor de açúcares de baixo peso molecular nas frutas (sacarose, glicose, frutose) pode comprometer o rendimento no processo de secagem, devido aderência do pó às paredes do secador; pois o pó produzido apresentará alta pegajosidade e higroscopicidade.

Neste sentido faz-se necessário o uso de agentes encapsulantes de alto peso molecular (polímeros e gomas) antes da atomização, para facilitar o processo de secagem, transporte e armazenamento das substâncias presentes nas frutas. Bhandari et al. (1997) relatam que a maltodextrina é um agente encapsulante comumente empregado na secagem por spray drying em função de sua baixa higroscopicidade, alta solubilidade em água fria e baixo custo.

A microencapsulação de substâncias quimicamente sensíveis, como o ácido ascórbico, por spray drying tem se mostrado viável para obtenção de sucos desidratados, concentrando as substâncias ativas típicas e protegendo-as em uma matriz polimérica contra oxidação. A vitamina $\mathrm{C}$ ou ácido ascórbico (AA) é uma vitamina hidrossolúvel e termolábil que se caracteriza como um antioxidante instável, facilmente oxidável, cujas ligações podem ser quebradas pelo oxigênio, substâncias alcalinas e temperaturas elevadas (AZULAY et al., 2003).

Com base nestas considerações o presente trabalho visa estudar a microencapsulação de ácido ascórbico (AA) a partir do suco de acerola verde in natura, usando maltodextrina como polímero encapsulante, avaliando-se a influência dos parâmetros de secagem spray drying (temperatura de secagem, fluxo de ar, vazão de alimentação e taxa de aspiração) sobre a composição, propriedades físico-químicas e teor de ácido ascórbico no pó.

\section{METODOLOGIA EXPERIMENTAL}

As acerolas foram colhidas no estágio de maturação verde, em pomar comercial no perímetro irrigado Tabuleiro de Russas, localizado na região do baixo vale do Jaguaribe (latitude Sul: 5³7’20”, longitude Oeste: $\left.38^{\circ} 07^{\prime} 08^{\prime \prime}\right)$ no Município de Limoeiro do Norte/Russas (CE), sendo as mesmas transportadas sob refrigeração para o Laboratório de Tecnologia Química do Instituto Federal do Ceará - Campus Fortaleza para posterior processamento e análise. Maltodextrina Maltogill@ 20DE (Cargill, Uberlândia-MG, Brasil) foi utilizada como polímero encapsulante.

$\mathrm{Na}$ etapa de processamento, as acerolas foram selecionadas manualmente para retirada de frutos danificados e em outros estágios de maturação, sendo em seguida higienizadas por imersão em $\mathrm{NaClO} 0,02 \%$. O suco de acerola verde in natura foi obtido usando uma centrífuga doméstica seguido de filtração em papel de celulose $(28 \mu \mathrm{m})$ para retirada do material em suspensão. 


\section{9 a 22 de outubro de 2014 \\ Florianópolis/SC}

A maltodextrina (polímero encapsulante) foi adicionada na proporção de $20 \%$ ao suco de acerola verde in natura e a mistura foi homogeneizada à temperatura ambiente $\left(25^{\circ} \mathrm{C}\right)$ até a completa dissolução de todos os componentes.

Para os estudos de secagem do suco in natura de acerola verde contendo maltodextrina foi utilizado um mini spray dryer modelo B-290 da Büchi ${ }^{\circledR}$. Todos os ensaios foram conduzidos em escoamento co-corrente utilizando-se um spray dryer duplo fluido com bico pulverizador de $0,7 \mathrm{~mm}$ de diâmetro. Inicialmente avaliou-se o efeito da temperatura $\left(165\right.$ e $\left.175{ }^{\circ} \mathrm{C}\right)$ sobre o rendimento de produção de ácido ascórbico por secagem spray drying, conforme recomendado por Barbosa (2010) e Moreira et al. (2009). Nesta parte dos experimentos foram mantidos constantes os parâmetros de: taxa de aspiração em 100\% (35 $\left.\mathrm{m}^{3} \cdot \mathrm{h}^{-1}\right)$, vazão de alimentação de $30 \%\left(9 \mathrm{~mL} \cdot \mathrm{min}^{-1}\right)$ e altura do rotâmetro em $40 \mathrm{~mm}$ (473 L.h ${ }^{-1}$ de ar). Para continuidade do estudo e otimização do processo de secagem in natura foram testadas taxas de aspiração de 25,30 e $35 \mathrm{~m}^{3} \cdot \mathrm{h}^{-1}$, vazões de alimentação de 9 e 15 mL.min ${ }^{-1}$ e fluxos de ar de 473 e 670 L.h $^{-1}$. Após cada corrida experimental, as amostras de pós obtidas foram armazenadas em potes herméticos no interior de dessecadores a vácuo até o momento da realização das caracterizações analíticas.

O suco de acerola verde in natura e o suco reconstituído (mistura obtida a partir da solução aquosa de pó de acerola verde $(0,6 \mathrm{~g}$ de pó de acerola verde $/ 100 \mathrm{ml}$ de água) foram caracterizados quanto à composição química, sendo determinados os teores de umidade, cinzas e proteínas de acordo com as metodologias descritas no Manual de Normas Analíticas, Métodos Químicos e Físicos de Alimentos do Instituto Adolfo Lutz (IAL, 2005) e açúcares totais pelo método do ácido 3,5dinitrosalicilico (DNS) descrito por Miller (1959). Experimentalmente, foram avaliadas ainda as características físico-químicas relacionadas ao teor de sólidos solúveis e $\mathrm{pH}$ usando um refratômetro digital Atago ${ }^{\circledR}$ PR 100 (AOAC, 1992) e um potenciômetro digital Orion Dual Star da Thermo Scientific $^{\circledR}$, respectivamente. $\mathrm{O}$ teor de vitamina $\mathrm{C}$ foi estimado utilizando o método do iodato de potássio, conforme descrito em IAL (2005). Para caracterização do pó de acerola verde, além das análises descritas anteriormente, foram investigados os parâmetros de solubilidade e higroscopicidade, conforme Barbosa (2010).

Para a análise estatística foi aplicado um delineamento experimental inteiramente casualizado sendo todos os experimentos realizados em triplicata para obtenção das médias das estimativas. A análise de variância para verificação da interação entre os fatores segundo teste de Tukey ao nível de $5 \%$ de probabilidade foi feita utilizando-se o programa ASSISTAT versão 7.7 beta.

\section{RESULTADOS E DISCUSSÕES}

A caracterização físico-química do suco in natura de acerola verde utilizado como material de entrada para obtenção do pó de acerola verde por secagem spray drying e do suco reconstituído obtido a partir deste está apresentada na Tabela 1. 
Tabela 1 - Características físico-químicas do suco de acerola verde in natura empregado na obtenção do pó de acerola verde e do suco reconstituído obtido a partir do pó produzido.

\begin{tabular}{|c|c|c|}
\hline Características & Suco in natura & Suco reconstituído \\
\hline Vitamina C (\%) & 2,8 & 2,5 \\
\hline Proteínas (\%) & 1,0 & 1,0 \\
\hline Umidade (\%) & 90 & 90 \\
\hline Açúcares totais (\%) & 5,7 & 5,5 \\
\hline Cinzas (\%) & 0,3 & 0,5 \\
\hline Outros (\%) & 0,2 & 0,5 \\
\hline Sólidos totais (g.100 ${ }^{-1}$ ) & 9 & 10 \\
\hline Sólidos solúveis ( ${ }^{\circ}$ Brix) & 7,5 & 7,4 \\
\hline $\mathrm{pH}$ & 3,4 & 3,4 \\
\hline
\end{tabular}

Os resultados da Tabela 1 mostram que tanto os sucos in natura de acerola verde como o reconstituído a partir do pó de acerola verde obtido por spray drying apresentam características físicoquímicas muito semelhantes sendo compostos principalmente de água, açúcares e vitamina C (98 a $99 \%$ da composição) e uma quantidade pequena (1 a 2\%) de proteínas, cinzas e outras substâncias menos importantes (lipídeos, fibras, etc). Ferreira et al. (2009) encontraram um teor de vitamina C para acerola no estágio de maturação verde de $2,2 \mathrm{~g} \cdot 100 \mathrm{~g}^{-1}$, resultado inferior ao encontrado no presente trabalho. Segundo Brunnini et al. (2004), variações no teor de vitamina C podem ocorrer em função do cultivo, manuseio, clima, solo entre outros fatores. Em geral, o suco reconstituído a partir do pó de acerola verde apresenta uma perda média de vitamina C de 10,7\% em relação a este, as quais podem ser atribuídas à degradação do ácido ascórbico durante o aquecimento ou por oxidação.

\subsection{Determinação das condições ótimas de secagem spray drying}

Testes preliminares realizados mostraram que quando se utiliza temperaturas de secagem abaixo de $150{ }^{\circ} \mathrm{C}$ o teor de umidade dos pós e sua higroscopicidade aumentam consideravelmente, prejudicando a fluidez dos mesmos. Segundo Moreira et al. (2009), essas características além de comprometerem a estabilidade do produto, também prejudicam sua recuperação, visto que grande parte do pó fica retido na câmara de secagem e no coletor do equipamento. Por outro lado temperaturas acima de $170{ }^{\circ} \mathrm{C}$ resultaram em maiores degradações do ácido ascórbico em função de sua termolabilidade.

A Tabela 2 mostra os resultados dos teores de ácido ascórbico (vitamina C) em relação à temperatura e a partir dos mesmos é possível afirmar que a temperatura de secagem apresenta efeito significativo $(p \leq 0,05)$ no teor de ácido ascórbico do pó de acerola. $\mathrm{O}$ aumento da temperatura resulta em uma diminuição no teor de vitamina $\mathrm{C}$ do pó de acerola verde. 
Tabela 2 - Efeito da temperatura de secagem sobre o teor de ácido ascórbico no pó de acerola verde obtido por atomização spray drying.

\begin{tabular}{|c|c|}
\hline Temperatura $\left({ }^{\circ} \mathrm{C}\right)$ & Vitamina C $\left(\mathrm{g} .100 \mathrm{~g}^{-1}\right)$ \\
\hline 165 & $18,6 \mathrm{a}$ \\
\hline 175 & $15,6 \mathrm{~b}$ \\
\hline
\end{tabular}

No teste de Tukey ao nível de 5\% de probabilidade, no qual as médias seguidas pela mesma letra na mesma coluna não diferem estatisticamente entre si. A temperatura de entrada de $165{ }^{\circ} \mathrm{C}$ apresentou a melhor resposta para o teor final em vitamina C. De acordo com Tonon et al. (2008), pós produzidos a temperaturas mais baixas tem uma tendência a aglomeração devido ao seu teor de umidade mais elevado, essa aglomeração reduz a exposição do pó ao oxigênio, o que favorece a proteção contra oxidação.

A Tabela 3 mostra os resultados para o tempo de secagem, teor de vitamina $\mathrm{C}$ e rendimento de obtenção do pó por secagem a $165^{\circ} \mathrm{C}$ a partir dos diferentes parâmetros opcionais investigados: taxa de aspiração, vazão de alimentação e fluxo de ar.

Tabela 3 - Valores médios a $165{ }^{\circ} \mathrm{C}$ para os teores de vitamina C (Vit. C), tempo de secagem e rendimento do pó (\%) em função das diferentes variáveis operacionais utilizadas na secagem spray

drying do suco de acerola verde.

\begin{tabular}{|c|c|c|c|c|c|c|}
\hline Amostra & $\begin{array}{c}\text { Taxa de } \\
\text { aspiração } \\
\left(\mathrm{m}^{3} \cdot \mathrm{h}^{-1}\right)\end{array}$ & $\begin{array}{c}\text { Vazão de } \\
\text { alimentação } \\
\left(\mathrm{mL}^{-1} \min ^{-1}\right)\end{array}$ & $\begin{array}{l}\text { Fluxo de } \\
\operatorname{ar}\left(L \cdot h^{-1}\right)\end{array}$ & $\begin{array}{c}\text { Tempo de } \\
\text { secagem } \\
\text { (min'seg”) }\end{array}$ & $\begin{array}{c}\text { Vit. C } \\
\left(\text { g. } 100 \mathrm{~g}^{-1}\right)\end{array}$ & $\begin{array}{l}\text { Rendimento } \\
(\%)\end{array}$ \\
\hline$P 1$ & 35 & 9 & 473 & 9'13" $\pm 2,5 " a b$ & $16,9 \pm 0,02 \mathrm{~b}$ & $66,1 \pm 0,13 b$ \\
\hline$P 2$ & 30 & 9 & 473 & 9’15" $\pm 2,0 ” a$ & $16,7 \pm 0,02 \quad d$ & $64,5 \pm 0,31 \mathrm{c}$ \\
\hline$P 3$ & 25 & 9 & 473 & $9 ' 11 " \pm 1,5 " \mathrm{~b}$ & $N D$ & $N D$ \\
\hline P4 & 35 & 15 & 473 & $6{ }^{\prime} 27 " \pm 1,0 ” \quad \mathrm{~d}$ & $15,8 \pm 0,02 \mathrm{c}$ & $54,4 \pm 0,02 d$ \\
\hline$P 5$ & 35 & 9 & 670 & $8 ’ 23 ” \pm 2,0 "$ c & $17,3 \pm 0,02 \mathrm{a}$ & $71,2 \pm 0,24 a$ \\
\hline
\end{tabular}

ND: Não determinado.

$\mathrm{Na}$ Tabela 3 não se observa diferença significativa para os tempos de secagem nas taxas de aspiração de 30 e $35 \mathrm{~m}^{3} \cdot \mathrm{h}^{-1}$ (amostras $P 1$ e $P 2$ ), e nesta condição para as respostas: teor de vitamina C e rendimento (\%) do pó foram observados valores médios de 16,8 g. $100 \mathrm{~g}^{-1}$ e $65,3 \%$; respectivamente. Experimentalmente a $25 \mathrm{~m}^{3} \cdot \mathrm{h}^{-1}$ (amostra $P 3$ ) houve caramelização do pó durante a operação, não sendo possível as estimativas de vitamina $\mathrm{C}$ e obtenção do rendimento do processo. Assim, tendo como base o resultado de vitamina $C$, adotou-se o valor da taxa de aspiração em $35 \mathrm{~m}^{3} \cdot \mathrm{h}^{-1}$ como valor ótimo para as operações subsequentes. $\mathrm{Na}$ amostra $P 5$ foram verificados os maiores teores de vitamina $\mathrm{C}$ e rendimento do processo. $\mathrm{O}$ aumento do rendimento neste caso está relacionado ao incremento do fluxo de ar quente que passa pelo pó durante o processo secagem, conforme observado por Almeida et al. (2006). 


\section{9 a 22 de outubro de 2014 \\ Florianópolis/SC}

Comparativamente, Sousa (2012), avaliando o microencapsulamento de camu-camu por spray drying a uma vazão de alimentação $25 \mathrm{~mL} \cdot \mathrm{min}^{-1}$ e fluxo de ar de 105 psi observou valores para teor de vitamina $C$ variando entre 6,5 e $8,9 \mathrm{~g} \cdot 100 \mathrm{~g}^{-1}$, os quais são bem inferiores aos encontrados nesta pesquisa. Na Tabela 4 estão apresentados os resultados relativos à caracterização físico-química do pó de acerola verde contendo ácido ascórbico microencapsulado produzido por secagem spray drying nas condições ótimas de operação, as mesmas utilizadas para produção da amostra $P 5$, conforme a Tabela 3.

Tabela 4 - Caracterização físico-química do pó de acerola verde contendo ácido ascórbico microencapsulado obtido por secagem spray drying a partir do suco in natura de acerola.

\begin{tabular}{|c|c|}
\hline Parâmetro & Pó de acerola verde \\
\hline pH (solução $1 \%)$ & 3,52 \\
\hline Vitamina C (\%) & 17,3 \\
\hline Umidade (\%) & 4,0 \\
\hline Sólidos totais $\left(\mathrm{g} .100 \mathrm{~g}^{-1}\right)$ & 96 \\
\hline Sólidos solúveis $\left({ }^{\circ} \mathrm{Brix}\right)$ & 100 \\
\hline Higroscopicidade $(\%)$ & 25,2 \\
\hline Solubilidade $(\%)$ & 98,8 \\
\hline
\end{tabular}

$\mathrm{Na}$ Tabela 4 observa-se que o valor encontrado na determinação do $\mathrm{pH}$, de 3,52; é semelhante ao encontrado por Figueirêdo et al. (2001), os quais avaliando o armazenamento de suco de acerola verde microencapsulado encontraram um $\mathrm{pH}$ médio de 3,5. Diferentemente, Tanaka (2007) em seu estudo da estabilidade de pó de acerola relatou um pH de 4,99.

O valor encontrado para a umidade do pó de acerola verde microencapsulado (4,0\%) assemelhase ao encontrado por Moura (2010), o qual encontrou um valor médio de 3,8\% em seu estudo de estabilidade do pó de acerola verde microencapsulado por spray drying. Tonon et al. (2008) investigando a secagem spray drying de suco de açaí obtiveram pós com teores de umidade na faixa de 0,64 a 2,89\% utilizando temperaturas de secagem de 138 a $202{ }^{\circ} \mathrm{C}$. Estes autores concluíram ainda que a temperatura de secagem tem relação direta como teor de umidade e higroscopicidade do pó, já que valores mais altos das mesmas resultam em pós com umidades mais baixas e com maior facilidade de adsorver água, ou seja, mais higroscópicos.

Ferrari et al. (2012) avaliaram a secagem de amora preta e obtiveram pós com higroscopicidade variando de 18,77 a $28,73 \%$, as quais se assemelham ao valor médio encontrado neste estudo (25,2 \%). Em relação aos sólidos solúveis (açúcares, ácidos orgânicos e outros constituintes) produziu-se um pó com $100{ }^{\circ}$ Brix, valor semelhante ao relatado por Silveira (2007) e Moura (2010) em suas pesquisas de secagem e estabilidade de suco acerola verde microencapsulado.

$\mathrm{O}$ pó produzido nas condições otimizadas apresentou uma concentração de vitamina $\mathrm{C}$ de 16,9\%; valor semelhante ao relatado por Menezes et al. (2009) e Tanaka (2010), que encontraram cerca de 17,2 e 17,8 \% de vitamina $\mathrm{C}$, respectivamente, em pós de acerola microencapsulados. 
O pó de acerola verde contendo ácido ascórbico microencapsulado apresenta ainda uma alta solubilidade $(98,8 \%)$, o que pode ser atribuído à elevada solubilidade da maltodextrina em água e a composição dos sólidos, basicamente representada por açúcares simples e ácidos orgânicos de cadeia curta. Este resultado corrobora com os valores encontrados por Barbosa (2010), que em sua pesquisa com sucos atomizados de mistura de frutas relatou valores de solubilidade entre 97,5 e 98,5\% para pós elaborados com concentrações de maltodextrina entre 12 e $15 \%$.

\section{CONCLUSÃO}

A eficiência do processo de secagem por spray drying em termos da concentração de vitamina C ou ácido ascórbico (AA) foi influenciada pelos parâmetros operacionais de temperatura de secagem, fluxo de ar, vazão de alimentação e taxa de aspiração. O pó produzido a uma temperatura de $165^{\circ} \mathrm{C}$ apresentou maior teor de vitamina C. As condições de secagem tidas com ótimas foram: vazão de alimentação de $9 \mathrm{~mL} \cdot \mathrm{min}^{-1}$, fluxo de ar de $473 \mathrm{~L} \cdot \mathrm{h}^{-1}$ e taxa de aspiração de $35 \mathrm{~m}^{3} \cdot \mathrm{h}^{-1}$. O pó de acerola verde contendo ácido ascórbico microencapsulado obtido nestas condições apresentou baixa higroscopicidade, alta solubilidade em água e um teor de ácido ascórbico de aproximadamente $17 \%$. A composição centesimal média para o suco reconstituído apresentou teores de $2,5 \%$ de AA; 0,5\% de cinzas, $1 \%$ de proteínas; $5,5 \%$ de açúcares totais e $90 \%$ de umidade.

\section{REFERENCIAS}

AlmeIDA, C. A.; GOUVEIA, J. P. G.; AlMEIDA, F. A.; SILVA, F. L. Avaliação da cinética de secagem em frutos de acerola. Biol. Ciênc. Terra, v. 6, p.145-151, 2006.

ASSOCIATION OF OFFICIAL ANALYTICAL CHEMISTRY. Official methods of analysis of the Association of Official Analytical Chemistry. Washington: AOAC, 1992.

AZULAY, M. M.; MANDARIM-DE-LACERDA, C.A.; PEREZ, M. A.; FILGUEIRA, A. L.; CUZZI, T. Vitamina C. An. Bras. Dermatol., v. 3, p. 265-274, 2003.

BARBOSA, S. J. Qualidade de suco em pó de mistura de frutas obtido por spray drying. Janaúba. (Dissertação de Mestrado). Universidade Estadual Montes Claros, 2010.

BHANDARI, B. R.; DATTA, N.; HOWES, T. Problems associated with spray drying of sugar-rich foods. Dry. Technol., v. 15, p. 671-684, 1997.

BRUNINI, M. A.; MACEDO, N. B.; COELHO, C. V.; SIQUEIRA, G. F. Caracterização física e química de acerolas provenientes de diferentes regiões de cultivo. Rev. Bras. Frutic., v. 26, p. 486489, 2004.

EASTMAN, J. E; MOORE, C. O. Cold water soluble granular starch for gelled food composition. U.S. Patent 4465702, 1984.

FERRARI, C. C.; RIBEIRO, C. P.; AGUIRRE, J. M. Secagem por atomização de polpa de amorapreta usando maltodextrina como agente carreador. Braz. J. Food Technol., v. 15, p. 157-165, 2012. 


\section{9 a 22 de outubro de 2014 \\ Florianópolis/SC}

FERREIRA, R. M. A.; AROUCHA, E. M. M.; SOUZA, P. A.; QUEIROZ, R. F.; PONTE-FILHO, F. S. T. Ponto de colheita da acerola visando à produção industrial de polpa. Rev. Verde, v. 4, p.13-16, 2009.

FIGUEIRÊDO, R. M. F.; GRNDIN, A.; MARTUCCI, E. T. Armazenamento do suco de acerola microencapsulado. Rev. Bras. Prod. Agroind., v. 3, p. 1-6, 2001.

INSTITUTO ADOLFO LUTZ. Normas analíticas, métodos químicos e físicos de alimentos. Edição digital. São Paulo, 2005.

MATSUURA, F. C. A. U.; CARDOSO, R. L.;FOLEGATTI, M. I. S.; OLIVEIRA, J. R. P.; OLIVEIRA,J. A. B.; SANTOS, D. B. Avaliações físico-químicas em frutos de diferentes genótipos de acerola (Malpighiapunicifolia D.C.). Rev. Bras. Frutic., v.23, n.3, p.602-606, 2001.

MENEZES, A. R. V.; JUNIOR, A. S.; CRUZ, H. L. L.; ARAUJO, D. R. A.; SAMPAIO, D. D. Estudo comparativo do pó da acerola verde (Malphigia emarginata D.C) obtido em estufa por circulação de ar e por liofilização. Rev. Bras. Prod. Agroind., v. 11, p. 1-8, 2009.

MILLER, G. L; Use of dinitrosalicylic acid for determination of reducing sugar. Anal. Chem. v. 11, p. 426-428, 1959.

MOREIRA, G. E. G.; COSTA, M. G. M.; SOUZA, A. C. R.; BRITO, E. S.; MEDEIROS, M. F. D.; AZEREDO, H. M. C. Physical properties of spray dried acerola pomace extract as affected by temperature and drying aids. Food Sci. Technol., v. 42, p. 641-645, 2009.

MOURA, S. M. Estabilidade da acerola em pó oriunda do cultivo orgânico. (Dissertação de Mestrado). Universidade Federal do Ceará, 2010.

RITZINGER, R.; RITZINGER, C. H. S. R. Cultivo de fruteiras - acerola. Inf. Agropec., v. 32, p. 17 25. 2011.

SILVEIRA, R. W. Estabilidade da vitamina $C$ no processamento da acerola (Malpighia emarginata D.C) em pó em uma agroindústria no estado do Ceará. (Monografia de Especialização), Universidade Estadual do Ceará, 2007.

SOUSA, A. L. R. Estabilização de moléculas bioativas presentes em suco de camu-camu (Myrciariadubia (H.B.K) McVaugh) pela integração dos processos de osmose inversa, evaporação osmótica e atomização. (Dissertação de Mestrado), Universidade Federal Rural do Rio de Janeiro, 2012.

TANAKA, L. D. Influência da desidratação por spray drying sobre o teor ácido ascórbico no suco de acerola (Malpighia ssp). (Dissertação de Mestrado), Universidade Estadual Paulista Professor Júlio de Mesquita Filho, 2007.

TONON, R. V.; BRABET, C.; HUBINGER, M. D. Influence of process conditions on the physicochemical properties of açaí (Euterpeoleraceae Mart.) powder produced by srapy drying. $J$. Food Eng., v. 88, p. 411-418, 2008.

VENDRAMINI, A. L.; TRUGO, L. C. Chemical composition of acerola fruit (Malpighia glabra L.) at three stages of maturity. Food Chem., v. 71, p. 195-198, 2000. 